\title{
O DESMONTE DA LEGISLAÇÃO DE AGROTÓXICOS E AS AMEAÇAS PARA A SUSTENTABILIDADE
}

\author{
Liton Lanes Pilau Sobrinho1 \\ Dhieimy Quelem Waltrich ${ }^{2}$
}

RESUMO: O artigo objetiva apresentar o desmonte da legislação de agrotóxicos e as ameaças para a sustentabilidade, em face dos PL 3200/15 e o PL 1687/15, ambos apensados ao PL 6299/02. O último movimento data de 23/05/16, que designa Comissão Especial para parecer. Neste contexto, surge a necessidade de conscientização proposto por Boff, adequado, aos ensinamentos de Morin. O método de abordagem utilizado foi o indutivo, o método de procedimento foi o monográfico e a técnica de pesquisa foi a bibliográfica. As considerações finais confirmam a adequação do modelo de desenvolvimento sustentável trazido por Boff e Morin.

PALAVRAS-CHAVE: Legislação; Agrotóxicos; Ameaça; Sustentabilidade; Desenvolvimento.

\section{THE DISMANTLING OF AGROCHEMICAL LEGISLATION AND THE THREATS TO SUSTAINABILITY}

\begin{abstract}
The article aims to present the dismantling of pesticides legislation and the threats to sustainability, in the face of PL 3200/15 and PL 1687/15, both linked to PL 6299/02. The last movement dates from 05/23/16, which appoints Special Commission for opinion. In this context, the need for awareness proposed by Boff, appropriate to the teachings of Morin, arises. The method used was the inductive one, the procedure method was the monographic one and the research technique was the bibliographical one. The final considerations confirm the adequacy of the model of sustainable development brought by Boff and Morin.
\end{abstract}

KEYWORDS: Legislation; Pesticides; Threat; Sustainability; Development.

\footnotetext{
${ }^{1}$ Professor dos cursos de Mestrado e Doutorado no Programa de Pós Graduação Stricto Sensu em Ciência Jurídica da Universidade do Vale do Itajaí. Professor do Programa de Pós -Graduação Stricto Sensu Mestrado em Direito da Universidade de Passo Fundo. Pós - Doutor em Direito pela Universidade de Sevilha - US Espanha. Doutor em Direito pela Universidade do Vale do Rio dos Sinos - UNISINOS (2008). Mestre em Direito pela Universidade de Santa Cruz do Sul UNISC (2000). Possui graduação em Direito pela Universidade de Cruz Alta (1997). Passo Fundo/RS. Brasil. Currículo Lattes: http://lattes.cnpq.br/2413013286462855, e-mail: liton@uivali.br

${ }^{2}$ Doutoranda em Ciência Jurídica pela Universidade do Vale do Itajaí- UNIVALI - SC. Mestre em Direito pela Universidade de Santa Cruz do Sul”. Possui graduação em Direito pela Faculdade Meridional- IMED. Docente na Universidade Passo Fundo- RS - Brasil; Advogada. Currículo Lattes: http://lattes.cnpq.br/7618606084224909. Email: dhieimy@yahoo.com.br
} 


\section{INTRODUÇÃO}

O presente artigo tem como objetivo tecer algumas considerações acerca do desmonte promovido pelas propostas legislativas na Câmara dos Deputados contra a sustentabilidade, que significa, em linhas gerais, um açoite aos direitos sociais.

Leonardo Boff ao construir um modelo de sustentabilidade pautado na visão ecológico-social, demonstra preocupação em relação ao modelo de desenvolvimento padrão sustentável; o modelo das três pilastras, que defende que para ser sustentável, o desenvolvimento deve ser economicamente viável, socialmente justo e ambientalmente correto.

Tal conceito foi criado em 1990 pelo britânico John Elkington, fundador da ONG Sustainability, que se propõe exatamente a divulgar estes três momentos como necessários a todo desenvolvimento sustentável. Ademais, urge a necessidade de implantação do modelo apresentado por Boff, que se vale de uma visão ecológico-social: a prosperidade sem crescimento (melhorar a qualidade de vida, a educação, os bens intangíveis) e estabilizar o crescimento para permitir que os países pobres possam ter prosperidade com crescimento para satisfazer as necessidades de suas populações empobrecidas sem cair na cultura do consumismo, o que exige um processo de educação social.

Os objetivos específicos do presente artigo são: a) demonstrar que as propostas legislativas são uma grande ameaça à sustentabilidade, haja vista a visão ecológica-social de Leonardo Boff; b) apresentar a proposta de desenvolvimento sustentável por meio da educação de Edgar Morin; c) estudar os três pilares da sustentabilidade.

Para delimitação do tema, surge o seguinte problema: as propostas legislativas (PL 3200/15; PL 1687/15 e PL 6299/02) ameaçam às expectativas de um desenvolvimento sustentável, na medida em que possa conduzir a Sociedade mercantil a promover o desequilíbrio ambiental, das futuras gerações?

Como hipótese básica supõe-se que sim, que as alterações propostas comprometem o desenvolvimento sustentável proposto por Edgar Morin e Leonardo Boff, podendo conduzir a Sociedade à promover o desequilíbrio ambiental capaz de afetar as necessidades das futuras gerações.

Nesta linha, a segunda parte do presente trabalho se debruça em adequar a proposta de Leonardo Boff de acordo com os ensinamentos de Edgar Morin, que amplamente discorre acerca do conhecimento, e a necessidade de construção de uma educação dedicada à 
identificação da origem de erros, ilusões e cegueiras. Partindo disso, esboçam-se duas grandes finalidades ético-políticas do novo milênio: estabelecer uma relação de controle mútuo entre a Sociedade e os indivíduos pela democracia e conceber a Humanidade como comunidade planetária.

A educação deve contribuir não somente para a tomada de consciência de nossa "Terra-Pátria", mas também permitir que esta consciência se traduza em vontade de realizar a cidadania terrena. Segundo Edgar Morin, não possuímos as chaves que abririam as portas de um futuro melhor. Não conhecemos o caminho traçado. Podemos, porém, explicitar nossas finalidades: a busca da hominização na humanização, pelo acesso à cidadania terrena, fornecendo, portanto, condições ideais de sobrevivência.

Para o desenvolvimento do presente, o mesmo foi dividido em duas partes: a primeira realiza a apresentação das proposições legislativas, em contraponto aos conceitos extraídos da obra de Leonardo Boff -Sustentabilidade, o que é - O que não é, com foco na contradição dos termos sustentabilidade e desenvolvimento, na sequência, coma apresentação da teoria paradoxal das três pilastras.

Já a segunda parte, trata de refletir acerca do critério "educação", como forma de salvaguardar a civilização com o conhecimento necessário à tomada de consciência para a construção de um desenvolvimento sustentável, com base nas premissas de Edgar Morin, esculpidas na obra Ensenar a vivir - Manifiesto para cambiar La educación.

Como se pode observar, é fundamental o trabalho de conscientização e sensibilização no sentido de não serem mais admitidas nem toleradas, como exigência da Sociedade contemporânea e até mesmo da sustentabilidade da economia capitalista globalizada, a formação de novos passivos ambientais.

É importante remarcar que a finalidade precípua da proteção ambiental é a prevenção, principalmente mediante a incorporação das práticas de gestão e planejamento ambientais, atreladas à legislação, políticas, planos, programas e projetos de atividades concebidos e implementados sob a perspectiva do tripé da Sustentabilidade (econômica, ecológico-ambiental e social).

O método de abordagem utilizado foi o indutivo, o método de procedimento foi o monográfico e a técnica de pesquisa foi a bibliográfica. Foram também acionadas as técnicas 
do referente ${ }^{3}$, da categoria ${ }^{4}$, dos conceitos operacionais ${ }^{5}$, da pesquisa bibliográfica ${ }^{6}$ e do fichamento ${ }^{7}$.

A palavra Sociedade ${ }^{8}$, quando não estiver em transcrições literais, será grafada com o $\mathrm{S}$ em letra maiúscula.

\section{AS PROPOSIÇÕES LEGISLATIVAS PL 3200/15 E O PL 1687/15 E PL 6299/02 X A VISÃO ECOLÓGICO-SOCIAL DE LEONARDO BOFF}

Quando se trata de analisar proposições legislativas, importante se deter ao conteúdo das mesmas, ou seja, qual o seu núcleo e qual a pretensão de sua proposição.

Inicialmente, o PL 3200/15 apresenta uma Política de Estado para Defensivos Fitossanitários e de Produtos de Controle Ambiental, seus Componentes e Afins e uma nova sistemática para procedimentos de avaliações e registros a semelhança de países tais como Estados Unidos e Canadá que concentram tal atividade em um único órgão de governo. A ideia é que a ciência paute a matéria e afaste a subjetividade. (BRASIL a, 2015)

Para o autor de sua proposição, Deputado Covatti Filho, o assunto é estratégico para a competitividade agrícola do Brasil no exterior. Trata-se de ciência, tecnologia e inovação indispensáveis para a competitividade do agronegócio (empresarial e familiar), setor que é o principal responsável pelos saldos positivos da balança comercial nos últimos anos.

\footnotetext{
3"explicitação prévia do motivo, objetivo e produto desejado, delimitado o alcance temático e de abordagem para uma atividade intelectual, especialmente para uma pesquisa". (PASOLD, Cesar Luis. Prática da Pesquisa Jurídica e metodologia da pesquisa jurídica. Florianópolis: OAB/SC Editora, 2007, p. 241).

4 "palavra ou expressão estratégica à elaboração e/ou expressão de uma idéia". (PASOLD, Cesar Luis. Prática da Pesquisa Jurídica e metodologia da pesquisa jurídica, p. 229).

5 "definição estabelecida ou proposta para uma palavra ou expressão, com o propósito de que tal definição seja aceita para os efeitos das idéias expostas". (PASOLD, Cesar Luis. Prática da Pesquisa Jurídica e metodologia da pesquisa jurídica, p. 229).

6 "Técnica de investigação em livros, repertórios jurisprudenciais e coletâneas legais". (PASOLD, Cesar Luis. Prática da Pesquisa Jurídica e metodologia da pesquisa jurídica, p. 240).

7 "Técnica que tem como principal utilidade otimizar a leitura na Pesquisa Científica, mediante a reunião de elementos selecionados pelo Pesquisador que registra e/ou resume e/ou reflete e/ou analisa de maneira sucinta, uma Obra, um Ensaio, uma Tese ou Dissertação, um Artigo ou uma aula, segundo Referente previamente estabelecido". (PASOLD, Cesar Luis. Prática da Pesquisa Jurídica e metodologia da pesquisa jurídica, p. 233).

${ }^{8}$ A opção dos autores do presente artigo para este tipo de grafia se sustenta no seguinte argumento: "[...] se a Categoria ESTADO merece ser grafada com a letra E maiúscula, muito mais merece a Categoria SOCIEDADE ser grafada com a letra $\mathrm{S}$ em maiúscula, porque, afinal, a SOCIEDADE é a criadora e mantenedora do Estado! Por coerência, pois, se a criatura/mantida (Estado) vem grafada com E maiúsculo, também eprincipalmente a criadora/mantenedora (Sociedade) deve ser grafada com o S maiúsculo!”. Conforme PASOLD, Cesar Luiz. Metodologia da Pesquisa Jurídica: Teoria e Prática. 13 ed. rev. Florianópolis: Conceito Editorial, 2015. p. 175. (negritos e destaques no original)
}

Rev. de Direito e Sustentabilidade | e-ISSN: 2525-9687 | Maranhão | v. 3 | n. 2 | p. 141-160 | Jul/Dez. 2017. 
Ainda, afirma que a mensagem repassada por todos é que a Lei $n^{\circ} 8.702$, de 1989, que dispõe sobre a pesquisa, a experimentação, a produção, a embalagem e rotulagem, o transporte, o armazenamento, a comercialização, a propaganda comercial, a utilização, a importação, a exportação, o destino final dos resíduos e embalagens, o registro, a classificação, o controle, a inspeção e a fiscalização, de agrotóxicos, seus componentes, e afins, deve ser revisada. Ademais, a referida norma apresenta-se como defasada ou incompatível com diversos conceitos, fundamentos e princípios dos tratados e acordos internacionais ratificados pelo Brasil, tais como o Acordo sobre a Aplicação de Medidas Sanitárias e Fitossanitárias (SPS)/OMC, internalizado pelo Brasil pelo Decreto 1.355/1994, em que os membros da OMC têm o direito de aplicar medidas sanitárias e fitossanitárias para a proteção da vida ou saúde humana, animal ou para preservar as plantas, desde que tais medidas não se constituam num meio de discriminação arbitrário entre países de mesmas condições, ou numa restrição encoberta ao comércio internacional. De forma semelhante, a atual redação da Lei desconsidera os critérios de classificação toxicológica de defensivos fitossanitários do Sistema Globalmente Harmonizado de Classificação e Rotulagem de Produtos Químicos (GHS), que foi adotado pela Organização das Nações Unidas, em 2002. É inquestionável, portanto, que o atual modelo de execução e aplicação da Lei no 8.702, de 1989, está esgotado, não consegue responder à atual realidade e expectativas da Sociedade. A Lei de Agrotóxicos deve ser repensada e reformulada para atender aos anseios da Sociedade.

Neste cenário, a referida proposta substitui a atual Lei de Agrotóxicos (7.802/89), que é revogada pelo texto, sendo inclusive o nome agrotóxico substituído por "defensivos fitossanitários e produtos de controle ambiental”. O projeto institui, na estrutura do Ministério da Agricultura, Pecuária e Abastecimento, a Comissão Técnica Nacional de Fitossanitários ${ }^{9}$ $\left(\mathrm{CTNFito}^{10}\right)$, com a finalidade de apresentar pareceres técnicos conclusivos aos pedidos de

\footnotetext{
${ }^{9}$ Entre as competências da CTNFito estabelecidas pelo projeto, estão: avaliar os pleitos de registro de novos produtos técnicos e emitir pareceres técnicos conclusivos nos campos da agronomia, toxicologia e ecotoxicologia sobre os pedidos de aprovação de registros de produtos; avaliar e homologar relatório de avaliação de risco de novo produto ou de novos usos em ingrediente ativo; analisar propostas de edição e alteração de atos normativos sobre a matéria; - apoiar tecnicamente os órgãos competentes no processo de investigação de acidentes e de enfermidades verificadas nas atividades com produtos defensivos agrícolas; - estabelecer diretrizes e medidas que possam reduzir os efeitos danosos desses produtos sobre a saúde humana e o meio ambiente; identificar no âmbito das atividades com produtos defensivos aquelas potencialmente causadoras de significativa degradação do meio ambiente; manifestar-se sobre os pedidos de impugnação de produtos defensivos fitossanitários. (BRASIL. CÂMARA DOS DEPUTADOS. Inteiro Teor da PL 3200/15)

${ }^{10}$ De acordo com o projeto, a CTNFito será composta por 23 membros, designados pelo ministro da Agricultura, com a seguinte composição: 15 especialistas de notório saber científico e técnico, das áreas de química, biologia, produção agrícola, fitossanidade, controle ambiental, saúde humana e toxicologia; representantes de cinco ministérios (Agricultura; Desenvolvimento, Indústria e Comércio; Meio Ambiente; Saúde e; Ciência, Tecnologia
} 
avaliação de novos produtos defensivos fitossanitários, de controle ambiental, seus produtos técnicos e afins. A comissão vai centralizar várias competências que estão hoje distribuídas entre outros órgãos, como Instituto Brasileiro do Meio Ambiente e dos Recursos Naturais Renováveis (Ibama), Agência Nacional de Vigilância Sanitária (Anvisa) e Ministério da Agricultura ${ }^{11}$."

No que tange ao PL $1687 / 15^{12}$, a proposta visa alterar a Lei $\mathrm{n}^{\circ} 7.802$, de 11 de julho de 1989, para instituir a Política Nacional de Apoio aos Agrotóxicos e Afins de Baixa Periculosidade, e tem como autora a Ex-Senadora Ana Rita, que justificativa, que a lei e o

e Inovação); um representante de órgão legalmente constituído de proteção à saúde do trabalhador; um representante de órgão legalmente constituído representativo do produtor rural; um representante de associações legalmente constituídas de produtores de defensivos.O mandato dos membros da CTNFito será de dois anos, permitida a recondução. A pessoa que fizer parte da comissão como membro titular, só poderá ser indicada novamente como membro do colegiado após três anos de seu desligamento. Conforme o texto, o ministro da Agricultura designará um dos membros da CTNFito para exercer a presidência, a partir de lista tríplice elaborada pelo colegiado. (BRASIL. CÂMARA DOS DEPUTADOS. Inteiro Teor da PL 3200/15)

${ }^{11}$ Conforme a proposta, os ministérios da Agricultura e do Meio Ambiente deverão emitir registros de novos produtos fitossanitários e de controle ambiental em até 30 dias após a data de emissão do parecer conclusivo da CTNFito. Tal qual a Lei de Agrotóxicos atual, o projeto de lei traz normas para a expedição da Permissão Experimental Temporária para novos produtos destinados à pesquisa e à experimentação. Além disso, traz normas para outros tipos de registro, como de produtos idêntico e de exportação, e fixa valores de taxas de avaliação e de registro.(BRASIL. CÂMARA DOS DEPUTADOS. Inteiro Teor da PL 3200/15).

${ }^{12}$ Art. $1^{\circ}$ A Lei $\mathrm{n}^{\circ}$ 7.802, de 11 de julho de 1989, passa a vigorar acrescida do seguinte art. 12-B: "Art. 12-B. É criada a Política Nacional de Apoio aos Agrotóxicos e Afins de Baixa Periculosidade, com os seguintes objetivos: I - promover o uso de agrotóxicos e afins de baixa periculosidade; II - disponibilizar novas tecnologias ao produtor rural, a baixo custo e de fácil manuseio; III - obter produtos agropecuários e florestais mais saudáveis; IV promover a capacitação do produtor rural no manuseio e na aplicação de agrotóxicos e afins de baixa periculosidade; $\mathrm{V}$ - contribuir para a preservação do equilíbrio dos recursos naturais. $\S 1^{\circ}$ São considerados agrotóxicos e afins de baixa periculosidade os produtos e agentes de processos físicos, químicos ou biológicos que se enquadrem nos termos do inciso I do art. $2^{\circ}$ desta Lei e que possuam as seguintes características: I - pouca ou nenhuma toxicidade ao ser humano e ao meio ambiente, de acordo com critérios estabelecidos pelo órgão federal responsável; II - eficiência agronômica no combate à ação danosa de seres vivos considerados nocivos à produção; III - não favorecimento a ocorrência de formas de resistência de pragas e de microrganismos; IV - custo reduzido para o produtor rural na aquisição e no emprego do produto; $\mathrm{V}$ - simplicidade de manejo e de aplicação. $\S 2^{\circ} \mathrm{O}$ Poder Público estimulará o financiamento de pesquisas científicas e tecnológicas para o desenvolvimento de agrotóxicos e afins de baixa periculosidade, utilizando recursos do Fundo Nacional de Desenvolvimento Científico e Tecnológico (FNDCT), instituído pela Lei n ${ }^{\circ} 11.540$, de 12 de novembro de 2007, e do Fundo Nacional de Meio Ambiente, instituído pela Lei no 7.797, de 10 de julho de 1989, nos termos do regulamento desta Lei, devendo ser priorizada: I - a busca de produtos agronomicamente eficientes e de baixa periculosidade ao ser humano e ao meio ambiente; II - a oferta de produtos que possam suprir a necessidade de controle de pragas e doenças em culturas desprovidas de alternativas ou para cujo controle os métodos disponíveis não mais se mostrem eficazes; III - a oferta de produtos com custo reduzido para aquisição e utilização e simplicidade de manejo e aplicação. $\S 3^{\circ} \mathrm{O}$ Poder Público estabelecerá programas específicos de incentivo ao estabelecimento de unidades industriais para a produção e distribuição de agrotóxicos e afins de baixa periculosidade e de estímulo aos produtores rurais para a sua utilização, prestando apoio creditício, assistência técnica e capacitação necessários. $§ 4^{\circ}$ O Poder Público estimulará os produtores rurais a utilizarem agrotóxicos não sintéticos de origem natural por meio de linhas de crédito com taxas de juros inferiores às concedidas para aquisição de agrotóxicos convencionais, nos termos do regulamento." Art. $2^{\circ}$ Esta Lei entra em vigor na data de sua publicação. (BRASIL. CÂMARA DOS DEPUTADOS. Inteiro Teor da PL 1687/15). 
Decreto 4.074/02, que a regulamentou, não adotam o termo "defensivo natural". (BRASIL, 2015, a)

Ela explica que manteve o uso do termo "agrotóxico não sintético de origem natural", por entender que a definição contida na lei já contempla o grupo de defensivos naturais, e que a adoção do termo "defensivos naturais" na lei provocaria uma polêmica que prejudicaria a discussão da proposta. A autora da proposta defende que os agrotóxicos naturais e causam baixo impacto ambiental, se comparados aos sintéticos, porque são mais facilmente decompostos na natureza. "Esses defensivos podem ser usados para melhorar o transporte e a vida útil dos produtos agrícolas e não deixam resíduos, abrindo portas para os mercados de exportação. Alguns são usados na produção orgânica, onde existem poucas opções tecnológicas", diz a justificativa do projeto. Segundo a autora, se usados em combinação com defensivos sintéticos, têm demonstrado melhor eficiência, melhores rendimentos e aumento da lucratividade da lavoura. De acordo com o texto, para ser considerado biopesticida, o produto deve ter baixo custo, ser de simples manuseio e não favorecer o surgimento de formas mais resistentes de pragas agrícolas, além de ser pouco agressivo à natureza. $\mathrm{O}$ projeto prevê a utilização de recursos do Fundo Nacional de Desenvolvimento Científico e Tecnológico (FNDCT) para o financiamento de pesquisas científicas e tecnológicas para o desenvolvimento de agrotóxicos naturais. O texto também obriga o Poder Público a financiar as empresas e produtores rurais que trabalhem com agrotóxicos não sintéticos de origem natural por meio de subsídios e linhas de crédito com baixas taxas de juros. Para Ana Rita, falta à agropecuária nacional uma legislação que se preocupe com o incentivo ao desenvolvimento dessas tecnologias, sua produção em escala industrial e seu uso no meio rural.“'Os novos padrões de consumo de alimentos sem contaminantes exigem maior sustentabilidade dos processos produtivos e o uso de defensivos naturais. Além disso, endemias e problemas de saúde 
pública e relacionados a desequilíbrios do meio ambiente podem ser sanados ou minimizados com o uso preferencial de defensivos naturais", justifica. (BRASIL, 2016)

Já o PL 6299/02, popularmente conhecida como a "PL do Veneno", altera os arts $3^{\circ} \mathrm{e}$ $9^{\circ}$ da Lei $n^{\circ} 7.802$, de 11 de julho de 1989, que dispõe sobre a pesquisa, a experimentação, a produção, a embalagem e rotulagem, o transporte, o armazenamento, a comercialização, a propaganda comercial, a utilização, a importação, a exportação, o destino final dos resíduos e embalagens, o registro, a classificação, o controle, a inspeção e a fiscalização de agrotóxicos, seus componentes e afins, e dá outras providências; tendo parecer: da Comissão de Seguridade Social e Família, pela rejeição deste e dos de nº 2495/00, 3125/00, 5852/01, 5884/05 e 6189/05, e da Comissão de Agricultura, Pecuária, Abastecimento e Desenvolvimento Rural, pela aprovação deste e dos de nº 2495/00, 3125/00, 5852/01, 5884/05 e 6189/05.

Em maio de 2016 ocorreu a apensação (anexação) do Projeto de Lei n. 3.200/2015 ao Projeto de Lei n. 1.687/2015. Este, por sua vez, foi apensado, em junho de 2016, ao PL 6299/02. No momento, o Projeto aguarda elaboração de Parecer da Comissão Especial destinada a proferir parecer ao Projeto de Lei no 6299 de 2002.

Como visto, todos os projetos tendem a ameaçar a sustentabilidade e conseqüentemente, o desenvolvimento sustentável. Leonardo Boff ao oferecer sua obra Sustentabilidade, o que é - O que não é, cumpriu com o papel de informar a Sociedade a real necessidade de se criar uma aliança de cuidado e proteção a Terra, a vida humana e a toda a comunidade de vida, superando os riscos, mediante uma sustentabilidade real, efetiva e global.

O que se sabe, é que a sustentabilidade aparece como uma questão de vida ou morte, e que a civilização humana corre riscos que ameaçam o futuro.

Por diversas vezes faz menções a Carta da Terra, que orientam seus escritos e conclamam toda a Sociedade à reflexão. Dito isto, necessário olhar a volta e verificar os inúmeros infortúnios e desequilíbrios que revestem o planeta, há um mal-estar generalizado, vive-se em uma insustentabilidade generalizada.

Para alguns, isso é consequência ou o resultado do modelo de produção e consumo industrial baseado na maximização do lucro e no desenvolvimento a qualquer preço. Trata-se da consolidação de uma Sociedade em situação periclitante de risco pluridimensional, em que 
a insegurança e a imprevisibilidade consubstanciam o componente básico e a única certeza decorrente das condutas humanas na atualidade. (BODNAR, 2013, p. 226.)

No entanto,

En el discurso dominante, muy propio de algunos sectores interesados en consolidar una determinada interpretación del desarrollo sostenible, ló que se nos plantea son una serie de opciones, aparentemente inexorables. O nos desarrollamos o volvemos a las cavernas. Pero esto no es así, con toda seguridad va a resultar preciso, a la vez, globalizar y desglobalizar, crecer y decrecer, desarrollar e involucionar, conservar y transformar. (FERRER, 2013, p. 13-14)

Com base nestas premissas, e com uma concepção firme para a execução flexível, Gabriel Ferrer (2013, p. 14) prefere falar de sustentabilidade antes de desenvolvimento sustentável, dizendo que a construção de uma Sociedade sustentável, supõe, ao menos que:

a) La sociedad que consideramos sea planetaria, nuestro destino es común y no cabe la sostenibilidad parcial de unas comunidades nacionales o regionales AL margen de lo que ocurra en el resto del planeta. Construir una comunidad global de ciudadanos activos es indispensable para el progreso de la sostenibilidad. Esta exigencia exige, entre otras cosas, el superar la parcial visión "occidental" -y, si se me apura, meramente anglosajona- que tenemos del mundo.

b) Alcancemos un pacto con la Tierra de modo que no comprometamos la posibilidad de mantenimiento de los ecosistemas esenciales que hacen posible nuestra subsistencia como especie en unas condiciones ambientales aceptables. Es imprescindible reducir drásticamente nuestra demanda y consumo de capital natural hasta alcanzar niveles razonables de reposición.

c) Seamos capaces de alimentar y, más aun, ofrecer una vida digna AL conjunto de los habitantes del planeta, acabando con 
injustificables desigualdades. Para ello es preciso reconsiderar y reformular los modos de producción y distribución de la riqueza. El hambre y la pobreza no son sostenibles.

d) Recompongamos la arquitectura social de modo que acabemos con un modelo opresor que basa el confort y progreso de unas capas sociales en La exclusión sistemática de legiones de desfavorecidos, huérfanos de cualquier oportunidad. Alcanzar un mínimo umbral de justicia social es una condición ineludible para caminar hacia la sostenibilidad.

e) Construyamos nuevos modos de gobernanza que aseguren La prevalencia del interés general sobre individualismos insolidarios, sean éstos de individuos, corporaciones o estados. Se trata de politizar la globalización, poniéndola al servicio de las personas y extendiendo mecanismos de gobierno basados en nuevas formas de democracia de arquitectura asimétrica y basadas.

Gabriel Ferrer (2013, p. 15) anota que o fundamento ético é um princípio jurídico que deve presidir a articulação destes direitos, mas a solidariedade é o pilar para a construção da Sociedade Global.

En su faceta ética o moral, el sentimiento de solidaridad nos impulsa a compartir venturas y desventuras con el "otro", a ponernos al lado Del desfavorecido, a percibir problemas y emociones ajenas como propios. En definitiva, a entender que lo ajeno también nos incumbe. Es lo que en psicología definirían como empatía y que desde esa ciencia se suele entender como una identificación intelectual, psíquica, emocional y afectiva entre sujetos, destacándose también en su dimensión de cohesionador social. (FERRER, 2013, p. 15)

Anote-se que em relação à "SUSTENTABILIDADE", tem-se um conceito aberto, permeável, ideologizado, subjetivo e relacional. O que é considerado sustentável num período de profunda crise econômica pode não ser num período de fartura. 
Para um indígena, determinada intervenção no meio ambiente são legítimas e compatíveis com a ideia de sustentabilidade, o mesmo comportamento pode não ter esta qualificação se é protagonizado por outra pessoa.

Em muitos casos, é até mais indicado adotar-se uma dimensão conceitual negativa, ou seja, muitas vezes é mais fácil identificar as situações de insustentabilidade. (CRUZ, 2012, p. 112-13)

A sustentabilidade foi inicialmente construída a partir de uma tríplice dimensão: ambiental, social e econômica. Na atual Sociedade do conhecimento é imprescindível que também seja adicionada a dimensão tecnológica, pois é a inteligência humana individual e coletiva acumulada e multiplicada que poderá garantir um futuro sustentável. Na perspectiva jurídica todas estas dimensões apresentam identificação com a base de vários direitos humanos e fundamentais (meio ambiente, desenvolvimento, direitos prestacionais sociais, dentre outros), cada qual com as suas peculiaridades e riscos. (CRUZ, 2012, p. 113)

Para a construção deste trabalho, adota-se a conceituação de Leonardo Boff (2015, p. 31-32) que segundo ele, remontam há 400 anos, e, os dicionários nos oferecem dois sentidos, um ativo e um passivo:

[...]o passivo diz que "sustentar" significa equilibra-se, manter-se, conservar-se sempre à mesma altura, conservar-se sempre bem. Nesse sentido "sustentabilidade", é, em termos ecológicos, tudo o que a Terra faz para que um ecossistema não decaia e se arruíne. Esta diligência implica que a Terra e os biomas tenham condições não apenas para conservar-se assim, como são, mas também possam prosperar, fortalecer-se e coevoluir.[...]O sentido ativo enfatiza a ação feita de fora para conservar, manter, proteger, nutrir, alimentar, fazer prosperar, subsistir, viver. No dialeto ecológico isso significa: sustentabilidade representa os procedimentos que tomamos para permitir que a Terra e seus biomas se mantenham vivos, protegidos, alimentados de nutrientes a ponto de vista de estarem sempre bem conservados e à altura dos riscos que possam advir. 
Leonardo Boff (2015, p. 37) afirma que hoje, o conceito é tão usado e abusado que se transformou num modismo, sem que seu conteúdo seja esclarecido ou criticamente definido". O que se sabe, é que fica cada vez mais clara a contradição existente entre a lógica do desenvolvimento de tipo capitalista, que sempre procura maximizar os lucros às expensas da natureza, criando injustiças sociais.

Necessita-se, atualmente, da consolidação de uma nova cultura de sustentabilidade global, baseada num paradigma de aproximação entre os povos e culturas, na participação do cidadão de forma consciente e reflexiva na gestão política, econômica e social. O direito do ambiente é a maior expressão de solidariedade que corresponde à era da cooperação internacional, a qual deve manifestar-se ao nível de tudo o que constitui o patrimônio comum da humanidade. Assim, somente com a consolidação de novas estratégias de governança transnacional, baseadas na cooperação e solidariedade, é que será possível assegurar um futuro com mais justiça e sustentabilidade. (CRUZ, 2012, p. 121)

A sustentabilidade como novo paradigma e objetivo da humanidade aparece assim como critério normativo para a reconstrução da ordem econômica (um novo sistema econômico mais justo, equilibrado e sustentável) da organização social (modificando a estrutura social e a organização da Sociedade - equidade e justiça social) do meio ambiente, possibilitando a sobrevivência do homem em condições sustentáveis e digna - respeito ao meio ambiente. (GLASENAPP, 2014, p. 69)

A governança ambiental, social e econômica, pressuposto básico para o alcance da sustentabilidade, pode ter muitas estratégias (institucionais ou não), com espaços de negociação, práticas educativas e participação da Sociedade civil, ferramentas que visam contribuir para o processo de construção de tomada de decisão compartilhada. (GLASENAPP, 2014, p. 72)

Para tanto, Leonardo Boff analisou criticamente a primeira formulação do tripé da sustentabilidade, que defende para ser sustentável, o desenvolvimento deve ser economicamente viável, socialmente justo e ambientalmente correto.

No que tange ao aspecto do desenvolvimento economicamente viável, Leonardo Boff (2015, p. 45-46) leciona que:

[...] sustentabilidade e desenvolvimento configuram uma contradição nos próprios termos. Eles tem lógicas que se autonegam: 
uma privilegia o indivíduo, a outra o coletivo; uma enfatiza a competição, a outra a cooperação; uma a evolução do mais apto, a outra a coevolução de todos juntos e inter-relacionados [...] a expressão desenvolvimento sustentável representa uma armadilha do sistema inoperante: assume os termos da ecologia (sustentabilidade) para esvaziá-lo e assume o ideal da economia (crescimento/desenvolvimento), mascarando, porém, a pobreza que ele mesmo produz.

Já no pilar "socialmente justo", Leonardo Boff $(2015,46)$ ilustra seus argumentos críticos com dados estatísticos que denunciam as injustiças mundiais, mas exemplifica os dados de nosso país, denunciando alarmantes desigualdades na distribuição das riquezas, pormenorizando dados da falsa retórica de um desenvolvimento socialmente justo, declarado pelo autor como "impossível dentro do atual paradigma de produção e consumo".

Na última pilastra “ambientalmente correto”, Leonardo Boff $(2015$, p. 47) afirma que:

[...] o atual desenvolvimento de faz movendo uma guerra irrefreável contra Gaia, arrancando dela tudo que lhe for útil e objeto de lucro, especialmente para aquelas minorias que controlam o processo. [...] o assalto aos commons privatizados por grandes corporações nacionais e multinacionais, está depauperando de forma perigosa a Mãe Terra, cada vez mais incapaz de se autorregenerar. O processo de produção de bens necessários para a vida e dos supérfluos que formam a grande maioria dos produtos é tudo, menos ambientalmente correto. Ao invés de falarmos dos limites do crescimento deveríamos falar dos limites de agressão à Terra e a todos os seus ecossistemas.

Em síntese, o modelo mercantil de desenvolvimento sustentável é vazio e retórico; proteger o que já foi adquirido em matéria ambiental não é um retrocesso ou o obstáculo ao desenvolvimento econômico. É garantir que um futuro é possível, no qual o ser humano deve interagir de forma responsável e solidária com todas as formas de vida da atual e das futuras gerações. Portanto, aos aplicadores do Direito Ambiental restam dois caminhos: uma postura 
cartesiana de inércia, formal e silogística frente aos movimentos legislativos que ora assolam o país, comprometendo todas as conquistas civilizatórias a partir de retrocessos irreversíveis; ou uma postura de coragem e coerência. (LEITE, 2014, p. 105).

Logo, perfeitamente possível afirmar que as referidas proposições legislativas são uma grande ameaça à sustentabilidade, haja vista que destoam da visão ecológica-social de Leonardo Boff. Sendo assim, resta a elucidação de um meio de salvaguarda para este momento importante, prestes às suas (des) aprovações, surge Morin, com o critério "educação", como mola precursora da conscientização e reconhecimento de existir a oferecer as futuras gerações, possibilidade de uma Sociedade pautada no desenvolvimento sustentável.

\section{O CRITÉRIO “EDUCAÇÃO” COMO FORMA DE SALVAGUARDA DA CIVILIZAÇÃO PARA UM DESENVOLVIMENTO SUSTENTÁVEL, COM BASE NAS PREMISSAS DE EDGAR MORIN}

Morin construiu sua obra Enseñar a vivir, Manifesto para cambiar la educacion com o propósito de trazer para essa nova geração de "formadores" um modelo distinto da lógica empresarial. Argumenta a necessita de que o objetivo do "ensino" é ensinar a viver, e viver, não é somente se adaptar as mudanças, principalmente, como viver na Sociedade de consumo na qual o ser humano resta inserido.

Edgar Morin afirma que estamos em uma civilização que não está pronta, que não tem o conhecimento necessário dos problemas globais, que não possui consciência da urgente reforma que precisa ser feita.

Sendo assim, o presente artigo se vale de seus ensinamentos para validar alguns caminhos propostos em sua obra, em consonância com as duras críticas que Leonardo Boff exarou ao modelo das três pilastras. A Sociedade, a comunidade mundial não pode mais ser conivente com políticas ditas sustentáveis, como modelos falidos de desenvolvimento sustentável, o modelo que a Sociedade de consumo compra e vende, precisa-se mais, busca-se mais, logo, este trabalho tem o condão de clarear este caminho, mostrando que é no próprio ser humano, em sua consciência, que deve brotar a semente da prevenção e da precaução.

Quando o cidadão se conforma com modelos de proposições legislativas que fazem do agronegócio a mola precursora do mercantilismo, e debatem "sustentabilidade" no mesmo 
barco em que ampliam as escalas autorizativas, corre-se o risco de se perder o fio condutor da linha tênue que mantém possível o futuro da civilização.

Quando Edgar Morin (2016, p. 87-88) se refere às cegueiras e os erros da educação, ele faz um alerta, ou melhor, indagações:

Es assombroso que la educación, que pretende comunicar los conocimientos, sea ciega acerca de lo que es el conocimiento humano, sus dispositivos, carencias, sus dificultades, sus propensiones al error y a la ilusión, y no se preocupe en absoluto de dar a conocer qué es el conocimiento. En efecto, el conocimiento no puede considerarse como una herramienta ready-made que se puede usar sin examinar su naturaleza. Por eso el conocimiento del conocimiento debe considerarse como una necesidad primordial que sirva de preparación para frontar los riesgos permanentes de error e ilusión que no cesan de parastar la inteligencia humana. Se trata de la armar las mentes para el combate vital por la lucidez. Es necesario introducir y derarrollar en enseñanza el estudio de las características cerebrales, mentales y culturales del conocimiento humano, de sus procesos y sus modalidades, de las disposiciones tanto psiquícas como culturales que exponen al error o la ilusión.

Ademais, Edgar Morin alerta que as universidades estão impondo critérios de eficácia, rentabilidade e competividade, ficando o sistema de ensino em caráter secundário. A questão primordial assusta, afinal, os números e estatísticas valem mais que tudo, o quantitativo elimina o qualitativo, o humanismo está em regressão devido a pressão tecnoeconômica.

A solução trazida por Edgar Morin (2016, p. 85-86) para enfrentar essa crise de consciência e humanismo é clara, como docentes,

debemos por supuesto resistirmos a la presión del pensamiento econocrático y tecnocrático haciéndonos defensores y promotores de la cultura, la cual exige superar la disynción entre ciencias y humanidades. Debemos mantener e recuperar una misión irremplazable, de la 
presencia concreta, la relación de persona e persona, el diálogo con el alumno para transmitir un fuego sagrado y elucidar juntos posibles malentendidos. Una misión personal que permite el reconocimiento de la calidad humana del alumno, le manifiesta benevolencia y atención, y no lo rechaza enviándolo a la categoría de los cretinos y los idiotas. Una misión personal que, ensenando la comprensión, hace comprender la necesidad inmediata de la comprensión en la clase, manifiesta en ella su comprensión y debería recibir comprensión como respuesta. Una misión personal que toma conciencia de que el peor dos males es la humillación del otro y le transmite esa conciencia al alumno, pues lo peor en las relaciones humanas es la humillación recíproca. La vía: salir del círculo vicioso de las humillaciones para entrar en el círculo virtuoso del reconocimiento mutuo.

O docente, como apontando por Edgar Morin, possui grande e honroso papel na formação da humanidade, pois, deve se dedicar, por conseguinte, à identificação da origem de erros, ilusões e cegueiras.

Ainda, menciona que o erro é subestimar o erro, haja vista que todo o progresso no desconhecido, todo o processo de adaptação exige postura forte e direcionada. Logo, quando nos calamos frente ao modelo padrão de desenvolvimento sustentável, imposto pelos mercados, subestimamos nossa própria capacidade mental de prevenir maiores desastres.

A Sociedade de consumo deixou de criar meios sustentáveis, deixou de se preocupar com o amanhã, e, muitos destes obstáculos ao modelo de desenvolvimento sustentável poderiam ser superados, se a inteligência humana fosse utilizada para situar as informações em um contexto conjunto. Com métodos que permitam aprender a construir relações mútuas e com influencias recíprocas entre as partes de todo o mundo complexo. (MORIN, 2016, p. 88)

O que precisa ser compreendido é que o conhecimento do erro permite superá-lo; sendo assim, pode-se afirmar que se a Sociedade se empoderar com a adequada e direcionada educação, terá, consequentemente, uma forma de salvaguarda de toda a civilização para um desenvolvimento sustentável. 
Por cada indivíduo carregar em si a gênese da espécie terrena, deve também carregar a consciência de que sendo parte deste planeta, não pode se valer de sua incompreensão para cometer erros em seu prejuízo.

El conocimiento ecológico se ha vuelto por tanto vital e urgente; es un conocimiento que permite, solicita y estimula la toma de conciencia con respecto a la degradación de la biosfera, que repercute de forma cada vez más peligrosa en la vida de los individuos, en la Sociedades y en la humanidad, y nos incita a tomar una serie de medidas indispensables. (MORIN, 2016, p. 115)

Desse modo, a arte de viver e buscar um pleno e saudável desenvolvimento exige de cada ser humano a consciência de que deve se despir de suas cegueiras, partindo-se da lógica construída por Boff, onde nossos hábitos e ações se coadunam as necessidades da Mãe Terra, unificando os esforços para que seja possível reduzir e evitar maiores desastres, como a possibilidade de aprovação das referidas propostas legislativas, que ameaçam às expectativas de um desenvolvimento sustentável, na medida em que conduzem a Sociedade mercantil a promover o desequilíbrio ambiental, das futuras gerações.

\section{CONSIDERAÇÕES FINAIS}

O presente artigo tratou de demonstrar que os projetos de Lei de n. ${ }^{\circ}$ 3200/15, 1687/15 e 6299/02 são uma grande ameaça à sustentabilidade, haja vista que destoam da visão ecológica-social de Leonardo Boff. Ainda, cumpre, pelo menos ao meio acadêmico, refletir e contribuir para que sejam construídas pospostas viáveis de desenvolvimento sustentável por meio da educação, que no presente, se debruça nas propostas de Edgar Morin.

No decorrer do trabalho, restou demonstrado que as propostas legislativas ameaçam às expectativas de um desenvolvimento sustentável, na medida em que conduzem a Sociedade mercantil a promover o desequilíbrio ambiental, das futuras gerações, caso as referidas proposições restem aprovadas.

Diante deste novo cenário que envolve as questões de sustentabilidade do planeta Terra, buscou-se com a doutrina de Edgar Morin, em especial, na sua obra Enseñar a vivir - 
Manifesto para cambiar La educación, preceitos que possam conduzir a comunidade humanitária em busca de um conhecimento verdadeiro e real, com noções reais de que o desenvolvimento a todo custo estará por comprometer o futuro das nações.

Diga-se de passagem, o dilema a ser enfrentado pela Sociedade global é como superar a escassez de recursos naturais diante do consumo exacerbado. Assim, pode-se dizer que o desenvolvimento sustentável não se pode valer da exploração dos recursos naturais, como também o novo modismo de economia verde coaduna com o processo de globalização por uma ecologia do desejo.

O desejo de ter, sim, um planeta que suporte as condições mínimas da subsistência sobre a terra e não a subsistência do mercado voraz pelo lucro. Sem ambiente não se é nada, a vida só se mantém na terra se souber utilizar seus recursos com respeito e dignidade.

Essa situação de degradação constante requer um esforço também sinérgico e cumulativo de todos na sua gestão e no controle a níveis de tolerabilidade. Essa "crise" deve ser entendida como alavanca propulsora ou chave que aciona a inteligência coletiva para atuar cooperativamente na definição dos destinos destas áreas.

Nestas condições, a crise atual não é apenas ecológica, é também uma crise de valores e de vínculos, reflexo da desvinculação progressiva de uma racionalidade axiológica em direção à razão técnica que muitas vezes distância e desvincula os seres humanos da natureza, na busca obstinada do desenvolvimento a qualquer custo.

Este quadro de patologia social deve ser apreendido e compreendido na atividade construtiva e transformadora da proteção ambiental. É nesse contexto que surge a preocupação científica com o desenvolvimento teórico dos princípios fundamentais que devem inspirar, orientar e promover todo o impulso construtivo e pedagógico a ser protagonizado.

A proteção do ambiente é um dever fundamental imposto não apenas aos Estados, mas também a todos os cidadãos. Este dever fundamental exige de todos um agir solidário em prol da proteção da natureza, implica também o ônus imposto a todos de participar ativamente das decisões e encaminhamentos relacionados ao interesse geral de um ambiente sadio e equilibrado.

Diante de todo o exposto comprova-se a hipótese básica de que o desenvolvimento sustentável em nosso país depende e muito de nossos representantes, haja vista que na eventual hipóteses das referidas proposições serem aprovadas, restará confirmado o desequilíbrio ambiental das futuras gerações, por isso, a importância de manter aceso o debate, com a 
realização de audiências públicas e a difusão entre a Sociedade dos ideários de Edgar Morin, que por meio da educação, pode-se promover o equilíbrio ambiental capaz de suprir as necessidades das futuras gerações.

\section{REFERÊNCIAS}

BODNAR, Zenildo; CRUZ, Paulo Márcio. O acesso à justiça e as dimensões materiais da efetividade da jurisdição ambiental.IN: SOUZA, Maria Cláudia da Silva Antunes de; GARCIA, Denise Schmitt Siqueira; RONCONI, Diego Richard. Direito ambiental, transnacionalidade e sustentabilidade. 1. ed. - Dados eletrônicos. - Itajaí: UNIVALI, 2013.

BOFF, Leonardo. Sustentabilidade: o que é, o que não é. 4 ed. Petrópolis, RJ: Vozes, 2015.

BRASIL. CÂMARA DOS DEPUTADOS. Inteiro Teor da PL 3200/15. Disponível em: < http://www.camara.gov.br/proposicoesWeb/prop_mostrarintegra?codteor=1412079\&filename $=\mathrm{PL}+3200 / 2015>$. Acesso em agosto de 2017.

CÂMARA DOS DEPUTADOS. Inteiro Teor da PL 1687/15. Disponível em: < http://www.camara.gov.br/proposicoesWeb/prop_mostrarintegra?codteor=1339815\&filename $=\mathrm{PL}+1687 / 2015>$. Acesso em agosto de 2017. A

CÂMARA DOS DEPUTADOS. Inteiro Teor da PL 6299/00. Disponível em: <http://www.camara.gov.br/proposicoesWeb/prop_mostrarintegra?codteor=1463789\&filena $\mathrm{me}=\mathrm{PL}+6299 / 2002>$. Acesso em agosto de 2017.

BRASIL, Emmanuele. Projeto institui a Política Nacional de Apoio ao Agrotóxico Natural. Agencia Câmara de Notícias. Disponível em: http://www2.camara.leg.br/camaranoticias/noticias/AGROPECUARIA/510028-PROJETOINSTITUI-A-POLITICA-NACIONAL-DE-APOIO-AO-AGROTOXICO-NATURAL.html. Acesso em agosto 2017.

CRUZ, Paulo Márcio; BODNAR, Zenildo. Globalização, transnacionalidade e sustentabilidade. Participação especial Gabriel Real Ferrer; org. e rev. Lucas de Melo Prado. - Dados eletrônicos. - Itajaí: UNIVALI, 2012.

FERRER, Gabriel. Sostenibilidad, transnacionalidad y trasformaciones del derecho.IN: SOUZA, Maria Cláudia da Silva Antunes de; GARCIA, Denise Schmitt Siqueira; RONCONI, Diego Richard. Direito ambiental, transnacionalidade e sustentabilidade. 1. ed. - Dados eletrônicos. - Itajaí: UNIVALI, 2013.

GLASENAPP, Maikon Cristiano; CRUZ, Paulo Márcio. Governança e sustentabilidade:constituindo novos paradigmas na pós-modernidade. IN: SOUZA, Maria Claudia da Silva de; GARCIA, Heloise Siqueira. Lineamentos sobre sustentabilidade segundo Gabriel Real Ferrer - Dados eletrônicos. - Itajaí: UNIVALI, 2014. 
LEITE, José Rubens Morato; BELCHIOR, Germana Parente Neiva. Diálogo das fontes, hermenêutica e princípio da proibição de retrocesso ambiental: uma nova fundamentação jurídico-reflexiva.IN: SOUZA, Maria Claudia da Silva de; GARCIA, Heloise Siqueira. Lineamentos sobre sustentabilidade segundo Gabriel Real Ferrer - Dados eletrônicos. Itajaí: UNIVALI, 2014.

MORIN, Edgar. Ensenar a vivir: manifiesto para cambiar la educación. Traducción de Núria Petit Fontsere. Paidós: Barcelona, 2016, p.: 87-88.

PASOLD, Cesar Luis. Prática da Pesquisa Jurídica e metodologia da pesquisa jurídica. Florianópolis: OAB/SC Editora, 2007. 